\title{
ARMONIZACIÓN Y UNIFICACIÓN DEL RÉGIMEN ECONÓMICO MATRIMONIAL EN LA UNIÓN EUROPEA: NUEVOS DESAFÍOS Y OPORTUNIDADES
}

\author{
HARMONIZATION AND UNIFICATION OF MATRIMONIAL \\ PROPERTY REGIMES IN THE EUROPEAN UNION: NEW CHALLENGES \\ AND OPPORTUNITIES
}

Pablo Quinzá Redondo*

\begin{abstract}
RESUMEN: El presente artículo, partiendo de la diversidad normativa sustantiva y conflictual del régimen económico matrimonial en los distintos Estados miembro de la Unión Europea, analiza los problemas a los que se enfrentan sus ciudadanos en relación con esta materia. En aras de superar dicha situación se toman en consideración los intentos de armonización y unificación llevados a cabo por instituciones u organismos internacionales. Tras llegar a la conclusión de la insuficiencia de todos ellos, se analiza el futuro escenario del régimen económico matrimonial desde el punto de vista de las acciones legislativas de la Unión Europea.
\end{abstract}

Palabras clave: Derecho internacional privado, régimen económico matrimonial, armonización, unificación.

ABSTRACT: This article seeks to analyse the regulation of matrimonial property regimes in the European Union from a substantive and a conflict-of-laws approach. The current situation generates a conjunction of problems to the European Union citizens which have not been dealt with on a global level in a definitive way. As a result the last part will describe the future scenario in matters of matrimonial property regimes in view of the legislative actions of the European Union.

Key words: Private international law, matrimonial property regimes, harmonization, unification.

\section{INTRODUCCIÓN}

Referirse actualmente a la Unión Europea, dejando de lado los objetivos políticos o económicos que esta vendría a cumplir, implica hacer mención a un espacio integrado caracterizado por la libre circulación de personas entre los diferentes Estados miembros y la progresiva importancia del fenómeno migratorio ${ }^{1}$. Nunca antes la movilidad e interconexión habían caracterizado a una Unión Europea tan pluricultural o multicultural como la

* Doctor en Derecho por la Universidad de Valencia y Profesor de Derecho internacional privado de la Pontificia Universidad Católica de Valparaíso. Dirección postal: Av. Brasil 2950, Valparaíso, Chile. Dirección electrónica: pablo.quinza@ucv.cl

1 Gómez Campelo (2008) pp. 17-18. 
actual $^{2}$, en la que motivos laborales o razones familiares o de índole económico relacionan, en mayor o menor medida, a ciudadanos de diferentes Estados miembro.

La consecuencia directa de dicho fenómeno sociodemográfico es que las relaciones personales entre ciudadanos de distintos Estados miembros han crecido exponencialmente, siendo ya harto frecuente encontrar parejas internacionales, en la que los sujetos que las componen ostentan distintas nacionalidades, diferentes residencias habituales o bien poseen bienes situados en diversos Estados miembros.

En particular, la Comisión Europea estima que aproximadamente 16 millones de matrimonios de los 122 existentes en la Unión Europea, esto es, el 13\%, presentan un elemento de extranjería. Cifras que vendrían a complementarse con datos relativos al divorcio transfronterizo del año 2007, en el que 140.000 de los 1.040.000 divorcios estuvieron conectados con distintos ordenamientos jurídicos ${ }^{3}$. Lo cierto es que cada vez que tiene lugar la disolución del vínculo matrimonial mediante dicha causal resulta necesario determinar el régimen de los bienes adquiridos durante la vigencia del régimen económico matrimonial, en aras de individualizar la propiedad de cada uno de ellos.

No significa lo anterior que el régimen de propiedad de los bienes sea únicamente relevante en supuestos relacionados con divorcio, pues también lo es durante la vigencia del matrimonio -especialmente para conocer si uno de los cónyuges puede disponer individualmente de un determinado bien- o con ocasión del fallecimiento de uno de los miembros de la pareja, pues antes de determinar la masa hereditaria a repartir entre los herederos -entre los que puede encontrarse el cónyuge supérstite- debe disolverse y liquidarse el régimen económico matrimonial.

Lamentablemente el incremento del número de matrimonios con elemento de extranjería no cuenta, en la actualidad, con un elenco normativo homogéneo e integrador elaborado por el legislador de la Unión Europea que dirima sobre el régimen de propiedad de los bienes adquiridos con razón de matrimonio. Una carencia que se presenta en dos niveles: el sustantivo y el conflictual. Mientras que con el primero se está haciendo referencia a la existencia en cada Estado miembro de la Unión Europea de distintos regímenes económico matrimoniales, tanto legales como opcionales para ser elegidos por los cónyuges mediante pactos o capitulaciones matrimoniales, el segundo pone de manifiesto la existencia de normas de Derecho internacional privado divergentes vis-à-vis.

Teniendo presente lo anterior, el objetivo del presente trabajo será analizar la diversidad normativa existente en los Estados miembro de la Unión Europea (1 y 2), para poner de manifiesto que dicha situación es el agente causante de, al menos, tres problemas jurídicos con una afección directa en los ciudadanos de la Unión Europea (4). Problemas todos ellos que, han intentado ser resueltos por distintas organizaciones o instituciones internacionales ajenas a la Unión Europea (5). Sin embargo, esta situación está en vías de alteración, siendo pues el fin último de la investigación dibujar el futuro panorama que en esta materia se prevé desde el punto de vista de las acciones legislativas de la Unión Europea (6).

\footnotetext{
2 Carlier (2002) p. 27.

3 Cifras extraídas de la Comunicación de la Comisión al Parlamento Europeo, al Consejo, al Comité Económico y Social Europeo y al Comité de las Regiones: Disipación de las incertidumbres en torno a los derechos patrimoniales de las parejas internacionales (COM (2011) $125 \mathrm{final}$ ).
} 


\section{LA REGULACIÓN SUSTANTIVA DEL RÉGIMEN ECONÓMICO MATRIMONIAL EN LOS ESTADOS MIEMBRO DE LA UNIÓN EUROPEA}

Como se ha hecho mención en la introducción, el fenómeno del régimen económico matrimonial, desde un punto de vista sustantivo o material, plantea un escenario caracterizado por la complejidad y heterogeneidad de soluciones, debido a la coexistencia de ordenamientos jurídicos que aportan respuestas diversas antes problemas jurídicos similares.

En los sistemas de derecho civil, en los que en términos generales podrían incluirse los ordenamientos jurídicos de todos los Estados miembro de la Unión Europea menos Reino Unido e Irlanda, el matrimonio genera desde su celebración una serie de consecuencias patrimoniales entre los cónyuges conocidas como régimen económico matrimonial. Se trata, no obstante, de un término que, a su vez, cubre dos realidades bien diversas.

En primer lugar, abarca un conjunto de disposiciones de carácter esencialmente patrimonial, que resultan indisponibles para las partes y que son de aplicación por el mero hecho del matrimonio. Relaciones jurídicas que incluyen los derechos y deberes generales de los cónyuges con contenido económico y que, en algunos Estados miembro como España o Francia, reciben el nombre de régimen económico matrimonial primario ${ }^{4}$. Algunos ejemplos de dicho régimen serían la independencia patrimonial de los esposos, el deber de información entre los cónyuges respecto de los bienes, ingresos y deudas de cada uno de ellos, la prestación de ayuda recíproca y la protección de la vivienda familiar.

Sin embargo, el verdadero núcleo de esta materia reside en el régimen económico matrimonial secundario, que presenta una doble tipología, la pactada o la legal. Con la primera de ellas se está haciendo referencia a la conclusión de pactos o capitulaciones matrimoniales cuyo fin último, si bien no el único ${ }^{5}$, consiste en la elección de un régimen económico matrimonial que se acomode a los deseos o preferencias de los cónyuges. Por su parte, el régimen económico matrimonial secundario legal recoge aquellos casos en los que los cónyuges no han manifestado su voluntad acerca del régimen de bienes del matrimonio, teniendo lugar la aplicación de aquellos regímenes previstos por el legislador de oficio. Aunque resulta innegable que la tipología de estos últimos es amplia y variada, lo cierto es que son susceptibles de incardinarse en regímenes comunitarios ${ }^{6}$, de participación ${ }^{7}$ y de

4 Boele-WOELKI et al. (2013) pp. 36-37.

5 Se está haciendo referencia, específicamente, a la posibilidad de incluir en los pactos o capitulaciones matrimoniales cláusulas que anticipen las consecuencias financieras del divorcio. Sobre esta cuestión véase VV.AA. (Añoveros Terradas 2010 y Cervilla Garzón 2013).

6 Los Estados miembro donde el régimen legal es de tipo comunitario son, entre otros, los siguientes: Bélgica (Art. 1398 Cc belga), Bulgaria (Art. 18 Código de familia búlgaro), Francia (Art. 1400 Cc francés), Hungría (Art. 27.1 ${ }^{\circ}$ párr. Ley de derecho de familia de Hungría), Italia (Art. 159 Cc italiano), Lituania (Art. 3.87 Cc lituano), Portugal (Art. 1717 Cc portugués), Rumania (Art. 312 Cc rumano) o España (Art. 1316 Cc español). Un supuesto especial lo constituye Holanda, donde salvo acuerdo en contrario de los cónyuges, rige una comunidad universal de bienes.

7 Pertenecerían a este grupo, en los Estados miembro, regímenes como la comunidad diferida de Dinamarca (Arts. 15 a 24 Ley danesa de los efectos legales del matrimonio), Finlandia (Arts. 34 a 40 Ley matrimonial de Finlandia) y Suecia (Cap. 7 Código matrimonial de Suecia) y la comunidad de las ganancias acumuladas de Alemania (Art. 1363 párr. 1 Cc alemán) y Grecia (Art. 1400 párr.1 y art. 1403 párr. 1 Cc griego). 
separación ${ }^{8}$, que presentan grandes peculiaridades por lo que respecta a la composición, administración y distribución del patrimonio en caso de disolución.

Sustancialmente opuesta es la solución existente en el derecho de Inglaterra y gales, en el que se desconoce la noción de régimen económico matrimonial ${ }^{9}$. En el common law inglés y galés el matrimonio no altera las propiedades de los cónyuges, si bien es cierto que sí existen una serie de consecuencias económicas "mínimas” desde que se produce su celebración. En particular, los cónyuges están obligados a proveerse de todo lo necesario entre ellos y respecto de sus hijos ${ }^{10}$, contribuir a las expensas del hogar ${ }^{11}$ y aceptar el régimen especial de protección de la vivienda familiar ${ }^{12}$.

En este sistema legal, el verdadero impacto patrimonial del matrimonio tiene lugar en el momento de su disolución, tanto en los casos de divorcio como de fallecimiento de uno de los cónyuges, para lo cual resulta relevante distinguir las situaciones en las que el cónyuge o los cónyuges han ejercido o no la autonomía de la voluntad.

En aquellos supuestos en que la disolución del matrimonio se produce por divorcio, los jueces ingleses y galeses tienen a su disposición un conjunto de orders para alcanzar la fairness - un resultado justo- entre los cónyuges ${ }^{13}$, haciendo uso de un enorme poder discrecional, para lo cual, de modo conjunto, deciden sobre las propiedades de los cónyuges y otras consecuencias económicas, en especial las obligaciones alimenticias ${ }^{14}$.

El punto de partida para realizar la distribución y asignación de los recursos de los cónyuges en casos de divorcio se encuentra en el art. 25.1 Matrimonial Causes Act 1973 (en adelante, MCA), que establece que el juez deberá tener en cuenta todas las circunstancias del caso, priorizando eso sí, el bienestar de los hijos menores del matrimonio. Una disposición complementada con lo establecido en el art. 25.2 MCA que contiene un elenco de factores que el juez deberá valorar para justificar su decisión, tales como la duración del matrimonio o la conducta de los cónyuges.

\footnotetext{
8 Siendo este el régimen legal en los sistemas forales de Cataluña (Art. 231-10.2 Ley 25/2010, de 29 de julio, del libro segundo del Código civil de Cataluña, relativo a la persona y la familia), Baleares (Art. 3.1 Compilación de derecho civil de las Islas Baleares) y Valencia (Art. 44 Ley de régimen económico matrimonial valenciano), antiguos territorios de la Corona de Aragón en España.

9 Cfr. VV.A.A. (Lowe y Douglas, 2007, p. 129; Harris-short y Miles, 2011, pp. 117 y 163-167; Probert, 2012, pp. 99-100).

10 Arts. 1 y 2 Domestic Proceedings and Magistrates' Court Act 1978 (1978 C. 22),

11 Art. 1 Married Women's Property Act 1964 (1964 C. 19), modificado por Equality Act 2010 (2010 C. 15)

12 Arts. 30 a 32 Family Law Act 1996.

13 En particular, los Tribunales pueden emitir maintenance pending suit (art. 22 Matrimonial Causes Act 1973) (en adelante, MCA), financial provision orders -periodical payments y lump sum orders- (art. $23 \mathrm{MCA}$ ), property adjustments orders (art. $24 \mathrm{MCA}$ ), orders for sale of property (art. 24A MCA) y pension sharing orders in connection with divorce (art. 24B MCA). Este elenco de 5 financial orders componen básicamente el concepto de $A n$ cillary o Financial Relief, que desde Abril de 2011 (con la entrada en vigor de la Family Procedure Rules 2010), forma parte de los llamados Financial Remedies.

14 Resulta crucial en este punto enfatizar que las consecuencias financieras de un divorcio en Inglaterra y Gales no distinguen entre la partición de los bienes y la determinación de las obligaciones alimenticias, como en los sistemas de derecho civil. Se dice que las order emitidas por el Tribunal inglés y galés ofrecen un resultado global, llamado tool box (MiLes (2012) p. 93) o global package solution (DutTA (2010) p. 385).
} 
Junto a ello, la jurisprudencia de la Supreme Court parece poner de manifiesto que los cónyuges pueden diseñar y concluir, cada vez más, soluciones a medida ${ }^{15}$, mediante la conclusión de acuerdos matrimoniales, cuyo fin último es decidir sobre las consecuencias económicas en caso de ruptura de la unión conyugal ${ }^{16}$.

Por otro lado, en los casos en que tiene lugar el fallecimiento de uno de los cónyuges, el derecho de Inglaterra y Gales, diferencia los supuestos de sucesión intestada y testada, aportando soluciones específicas. En el primero de los casos, existe una partida económica y/o patrimonial que queda reservada para el cónyuge supérstite ${ }^{17}$, y en el segundo de ellos, el punto de partida es la libertad testamentaria que existe en el common law inglés y galés $^{18}$. Lo anterior se completa con la posibilidad de reclamar al juez competente una parte de los bienes del causante con independencia de lo que le haya correspondido por herencia, y siempre que el solicitante demuestre que la disposición testamentaria realizada por el causante o el resultado que se produciría en los supuestos de sucesión intestada, conducen a una provisión económica no razonable para él/ella ${ }^{19}$.

Todo lo anterior pone de manifiesto cómo muchas y variadas son las diferencias existentes no solo entre los ordenamientos jurídicos de tradición civilista y los de common law en el seno de la Unión Europea, sino también por lo que respecta a los Estados miembro incluidos en la primera de dichas familias jurídicas.

\section{LA REGULACIÓN CONFLICTUAL DEL RÉGIMEN ECONÓMICO MATRIMONIAL EN LOS ESTADOS MIEMBROS DE LA UNIÓN EUROPEA}

El tratamiento que recibe el régimen económico matrimonial en los distintos Estados miembros de la Unión Europea, resulta divergente no solo desde una vertiente sustantiva, tal y como se ha analizado en el epígrafe anterior, sino también, desde el punto de vista del Derecho internacional privado ${ }^{20}$, ya que la falta de unificación global de los criterios de ley aplicable provoca la aplicación de las normas de conflicto bien de origen convencional -Convenio de La Haya de 1978 sobre la ley aplicable a los regímenes matrimoniales ${ }^{21}$ y Convenio nórdico de 1931 en materia matrimonial ${ }^{22}$-, bien de origen estatal, en los Estados miembros de tradición civilista y la lex fori en el common law de Inglaterra y Gales.

15 En otras palabras, de entre todas las circunstancias del caso (art. 25.1 MCA), podrá encontrarse la conclusión por parte de los cónyuges de un acuerdo matrimonial en el que determinen anticipadamente las consecuencias financieras de su eventual divorcio.

16 La eficacia jurídica de los acuerdos matrimoniales en Inglaterra y Gales ha dependido tradicionalmente del momento de su celebración. Un análisis de la evolución de los mismos puede encontrarse en GASPAR LERA (2012) pp. 1-25.

17 Inheritance and Trustee's Act 2014 (2014 C.16).

18 Wills Act 1837 (1837 C.26, Regnal. 7 Will 4 and 1 Vict).

19 Inheritance Act 1975 (1975, C. 63)

20 Libro Verde sobre el conflicto de leyes en materia de régimen matrimonial, con especial referencia a las cuestiones de competencia jurisdiccional y reconocimiento mutuo (COM (2006) 400 final).

21 Norma de conflicto aplicable al régimen económico matrimonial en Francia, Luxemburgo y Holanda. Para un análisis más detallado de dicho Convenio véase el epígrafe 5.3 del presente trabajo.

22 Norma de conflicto aplicable al régimen económico matrimonial en Dinamarca, Suecia y Finlandia 
En este sentido, un examen detallado de las normas de conflicto de los Estados miembros cuyos ordenamientos jurídicos son de tradición civilista corrobora la existencia de una gran heterogeneidad, si bien es cierto que resulta posible distinguir, en casi todos ellos, las situaciones en las que los cónyuges han elegido la ley aplicable al régimen económico matrimonial de aquellas en las que no y que producen, como consecuencia, la toma en consideración por parte del juez que resuelve el litigio, de las conexiones objetivas incluidas en la norma de conflicto.

En relación con el primero de los supuestos, y teniendo presente que las primeras muestras de la aceptación de la autonomía de la voluntad conflictual en materia de derecho de familia tuvieron lugar en el sector de los efectos del matrimonio ${ }^{23}$, puede afirmarse que la práctica totalidad de las normas de conflicto de los Estados miembro recogen la posibilidad de elegir la ley aplicable al régimen económico matrimonial ${ }^{24}$. Una facultad, eso sí, que se presenta en distintos niveles, pues mientras algunas normas de conflicto permiten la elección absoluta del derecho aplicable a las relaciones económicas entre los cónyuges ${ }^{25}$, la gran mayoría ofrecen una libertad restringida a la elección de determinadas leyes ${ }^{26}$ para lograr un equilibrio razonable entre el principio de proximidad y la propia autonomía de la voluntad ${ }^{27}$. Una clasificación que, en mayor o menor medida, se extiende al cambio voluntario de la ley aplicable.

Del mismo modo, el grado de autonomía de la voluntad resulta también divergente en relación con el fraccionamiento o depeçage de la ley aplicable, existiendo un interesante debate sobre si las normas de conflicto deben primar la facilitación de la liquidación del régimen económico matrimonial y el aumento de la previsibilidad y seguridad jurídica que implica la elección de una única ley o si, por el contrario, deben admitir la designación de varias leyes, en especial, la lex rei sitae, para acercar el estatuto real al patrimonial y facilitar la armonía internacional de decisiones gracias al reconocimiento de sentencias y documentos públicos en los países donde se localizan los bienes ${ }^{28}$. Teniendo esto presente, las normas de conflicto de los Estados miembro presentan una triple tipología: la elección absoluta de varias leyes, la elección limitada de varias leyes y la elección de una única ley ${ }^{29}$.

\footnotetext{
23 Un detallado estudio del rol de la autonomía de la voluntad en esta materia así como su evolución histórica puede encontrarse en Diago Diago (1999) pp. 103-178.

24 La autonomía de la voluntad conflictual en materia de efectos económicos del matrimonio no parece estar permitida en Grecia (art. 15 CC griego), Hungría (art. 39 LDIPr Hungría de 1979) y Eslovaquia (art. 21 LDIPr Eslovaquia de 1993).

25 Como por ejemplo Austria (art. 19 LDIPr Austria).

26 Tal y como evidencian las normas de conflicto nacionales de España (art. 9.3 Cc español), Alemania (art. 15.2 Ley introductoria del Cc alemán), Bélgica (art. 49.1 LDIPr Bélgica), Rumania (art. 2590.2 Cc rumano), Italia (art. 30 LDIPr Italia), Estonia (art. 58.1 LDIPr Estonia), Polonia (art. 52 LDIPr Polonia), Bulgaria (art. 79.4 LDIPr Bulgaria), Eslovenia (art. 39.2 LDIPr Eslovenia), Croacia (art. 37.2 LDIPr Croacia) y Lituania (art. 1.28 Cc lituano) y las normas de conflicto convencionales, como el art. 3 del Convenio de La Haya de 1978 sobre la ley aplicable a los regímenes matrimoniales y el art. 3 de la Modificación del Convenio nórdico de 1931.

27 BONOMI (2006) p. 63.

28 VAquero López (2006) p. 203.

29 En este sentido, en aquellos Estados miembros en que se permite la autonomía de la voluntad conflictual ilimitada, nada parece impedir la elección de varias leyes (art. 19 LDIPr Austria). De otro lado, en la mayoría de Estado miembros únicamente es posible elegir una ley para regular el régimen económico matrimonial (DiAGO
} 
En segundo lugar, cuando los cónyuges no han elegido la ley aplicable al régimen económico matrimonial, existen dos principales tendencias en los diversos Estados miembros pertenecientes a la familia de derecho civil. Algunos recogen como primera conexión subsidiaria la nacionalidad ${ }^{30}$ y otros la residencia habitual ${ }^{31}$ en lo que supone una clara opción de política legislativa, pues mientras el primero de ellos responde al principio de soberanía del Estado y, a través del mismo, se pretende poner de relieve la vinculación del sujeto con el Estado del que es nacional, la segunda se caracteriza por su flexibilidad y adaptabilidad, al considerar la ley del Estado donde el sujeto vive y está integrado ${ }^{32}$.

Correlativamente, el empleo de puntos de conexión aplicables en ausencia de autonomía de la voluntad o cuando esta no está prevista en el Derecho internacional privado del Estado en cuestión, puede conducir a la aplicación de una nueva ley cuando la norma de conflicto no fija el punto de conexión en el tiempo ${ }^{33}$ o cuando prevé la mutabilidad automática de la ley aplicable $e^{34}$, generándose una situación de conflicto móvil. Se trata de Estados cuyas normas de conflicto parecen primar la aplicación de una ley conectada con las circunstancias actuales de los cónyuges ${ }^{35}$, aun sacrificando la seguridad jurídica ${ }^{36}$.

Por otro lado, en el common law de Inglaterra y Gales la regulación internacional privatista parte de una doble limitación en esta materia. En primer lugar, resulta lógico que si desde un punto de vista sustantivo se desconoce el concepto de régimen económico matrimonial, tampoco existan normas de conflicto que lo regulen ${ }^{37}$. Por otro lado, conviene

DiAgO (1999) p. 197). Finalmente un tercer grupo de Estados acogerían una postura intermedia consistente en la posibilidad de elección de la lex rei sitae (por ejemplo, art. 6 del Convenio de La Haya de 1978 sobre la ley aplicable a los regímenes matrimoniales, art. 15.2.3 Ley introductoria Cc alemán y art. 49.4 LDIPr República Checa).

30 La primacía de la nacionalidad se hace patente en sistemas jurídicos como el alemán (art. 14 Ley introductoria del Cc alemán), el búlgaro (art. 79.1 LDIPr Bulgaria), el italiano (art. 29 LDIPr Italia), el croata (art. 36.1 LDIPr Croacia), el húngaro (art. 39 LDIPr Hungría), el esloveno (art. 38 LDIPr Eslovenia), el eslovaco (art. 21.1 LDIPr Eslovaquia), el austríaco (art. 18.1 LDIPr Austria), el griego (art. 14 Cc Grecia), el polaco (art. 51 LDIPr Polonia) o el portugués (art. 52 Cc Portugal).

31 Primer punto de conexión en las normas de conflicto de Estados miembros como Rumania (art. 2589 Cc rumano), Bélgica (art. 48.1 LDIPr Bélgica), Lituania (art. 1.28 Cc lituano), así como en los Estados miembros que ratificaron el Convenio de La Haya de 1978 sobre la ley aplicable a los regímenes matrimoniales (art. 4) y el Convenio nórdico de 1931 (art. 3).

32 Un detallado elenco de las ventajas e inconvenientes de nacionalidad $v$ s. residencia habitual, aunque referido a la ley aplicable al divorcio en la Unión Europea, puede encontrarse en CALVo CARAVACA y CARrasCosa GONZÁLEZ (2014) pp. 254-259.

33 Por ejemplo, la norma de conflicto búlgara (art. 79.1 LDIPR búlgara), cuya primera conexión, la nacionalidad común, no se encuentra congelada en ningún momento del tiempo, pudiendo dar lugar a problemas de interpretación.

34 La mutabilidad automática de la ley aplicable está presente, empero, en una minoría de Estados miembros, como son los que han ratificado el Convenio de La Haya de 1978 sobre la ley aplicable a los regímenes matrimoniales (art. 7), así como aquellos vinculados por la Convención nórdica en materia matrimonial de 1931 (art. 3 subpárr. 2), Rumania (art. 2596.1 y 2 CC rumano) y, aparentemente, en Italia según VV.AA. (VIARENGo, 1996, pp. 259-262; Garofalo, 1997, pp. 169-170; Ballarino, 2011, pp. 164-167).

35 VON OVERBECK (1978) p. 366.

36 Cfr. VV.AA (Lequette, 1994, pp. 167-170, Courbe, 2007, p. 182; Mayer y Heuzé, 2010, p. 557, Clavel, 2012, pp. 429-430).

37 Kroll (2008) p. 382. 
tener presente que cuando los tribunales ingleses y galeses tienen competencia para resolver disputas referentes a la distribución y asignación de los recursos de los cónyuges en casos de divorcio aplican el derecho inglés y galés, esto es, la lex fori, con independencia de los ordenamientos jurídicos relacionados con el supuesto de hecho ${ }^{38}$.

Sin embargo, si bien es cierto que es la ley del foro la que resulta de aplicación para determinar el reparto patrimonial en caso de un eventual divorcio -de acuerdo con lo analizado en el epígrafe anterior-, lo cierto es que sí resulta relevante determinar su ley reguladora para resolver, por ejemplo, las disputas de los propios cónyuges acerca de la propiedad, conjunta o privativa, de un determinado bien, especialmente en los procedimientos relacionados con terceros ${ }^{39}$.

Ante este tipo de situaciones, el common law inglés y galés distingue las situaciones en las que los cónyuges han celebrado acuerdo matrimonial de aquellas en las que no, aportando soluciones diferenciadas. Así, en primer lugar, la autonomía de la voluntad, expresa o táctica, permite a los cónyuges elegir el ordenamiento regulador del sistema de propiedad de un determinado bien ${ }^{40}$. De otra parte, cuando no existe manifestación de voluntad alguna, la práctica jurisprudencial propone para el caso de los bienes muebles estar a la ley domiciliar común ${ }^{41}$ y en ausencia del mismo a la ley del país que presente los vínculos más estrechos con los cónyuges y, tratándose de bienes inmuebles, la aplicación de la ley del lugar de situación de los bienes inmuebles o la ley domiciliar común ${ }^{42}$.

\section{PROBLEMAS ASOCIADOS A LA REGULACIÓN SUSTANTIVA Y CONFLICTUAL DEL RÉGIMEN ECONÓMICO MATRIMONIAL EN LA UNIÓN EUROPEA}

La circunstancia fáctica del incremento de matrimonios internacionales, acompañado de un marco jurídico disperso y diverso, tanto en el plano material (2) como conflictual (3), son los factores potencialmente generadores de ciertas actitudes peligrosas. Se está haciendo referencia a lo que doctrinalmente se ha denominado forum shopping o "carrera hacia los tribunales" (4.1) y law shopping o "turismo de leyes" (4.2), en los que los cónyuges pueden generar activamente una situación jurídica inesperada. Al mismo tiempo, esta discrepancia de los legisladores genera necesariamente una inseguridad jurídica, en la que quedan atrapados los cónyuges poco previsores o inactivos (4.3).

\footnotetext{
38 FawCett y Carruthers (2008) p. 1068.

39 Clarkson y Hill (2006) p. 435.

40 Cfr. VV.AA. (Clarkson y Hill, 2006 p. 442; Collins, 2012, p. 1472).

41 Sobre esta cuestión véanse las sentencias de los casos Frankel's Estate v The Master 1950 (1) S.A. 220 (AD) y Re Egerton's Will Trusts [1956] Ch. 593.

42 Mientras que en la sentencia del caso Welch $v$ Tennent [1891] A.C. 639 parece optarse por la ley del lugar de situación de los bienes inmuebles, en Re De Nicols [1900] 2 Ch 410, el fallo de la sentencia se inclina por la ley domiciliar común.
} 


\subsection{EL FORUM SHOPPING}

Uno de los problemas "clásicos" del Derecho internacional privado, y que en cierta medida vendría a justificar su propia existencia, es el del forum shopping o carrera hacia los tribunales, consistente en plantear la demanda ante los tribunales del Estado donde una o varias partes esperan obtener el pronunciamiento más favorable para sus intereses a través de ciertas ventajas procesales o relativas a la ley aplicable al supuesto de hecho ${ }^{43}$. Un fenómeno que, pese a resultar especialmente protagonista en litigios contractuales o societarios, donde las cantidades económicas en liza pueden ser altamente cuantiosas, también presenta una especial relevancia en derecho de familia ${ }^{44}$ o sucesiones $^{45}$.

En particular, en el sector del régimen económico matrimonial, y partiendo de la circunstancia de que en el momento presente no ha tenido lugar una unificación de las normas de Derecho internacional privado de los Estados miembros ni una armonización o unificación del derecho sustantivo, lo cierto es que, cuando los cónyuges no hayan celebrado pactos o capitulaciones matrimoniales, la ley designada en virtud de los criterios de conexión previstos en la norma de conflicto del tribunal que conoce del asunto, conducirá a la aplicación del régimen económico matrimonial legal previsto en tal ordenamiento jurídico.

Esta situación puede provocar resultados discordantes, dependiendo del foro que conozca del asunto concreto y del ordenamiento jurídico que finalmente aplique, ya que los sistemas de régimen económico matrimonial resultan divergentes en todos los niveles y la concreta aplicación de una u otra norma de derecho sustantivo varía materialmente el resultado del supuesto particular ${ }^{46}$.

\subsection{El LAW SHOPPING}

El hecho de que en algunos ordenamientos jurídicos no resulte posible optar por la autonomía de la voluntad conflictual así como la circunstancia de que, en aquellos Estados donde está permitida, no pueda ejercerse con la misma amplitud, produce como consecuencia directa la potenciación del law shopping, que implica que los cónyuges que tengan especial interés en que determinada ley rija sus relaciones patrimoniales, bien antes de contraer matrimonio, bien durante el transcurso del mismo al desear alterar el ordenamiento jurídico aplicable, acudirán ante las autoridades del Estado Miembro cuya legislación les permita tal elección.

\footnotetext{
43 Batiffol (1974) p. 90.

44 Recuérdese que el riesgo de forum shopping fue también una de las razones que motivaron la aparición del Reglamento Roma III, como consecuencia de la alternatividad de los fueros del Reglamento Bruselas II bis y la, hasta entonces, inexistente unificación conflictual en la materia. Esta cuestión ha sido intensamente discutida por VV.AA. (SÁnchez Jiménez, 2013, pp. 41-44; Queirolo y Carpaneto, 2012, pp. 59-86; Meeusen, 2007, p. 264; Di Filippo, 2005, pp. 202-203; GonzÁlez Beilfuss, 2004, p. 167; Borrás, 2003, p. 373; Dethloff, 2003, p. 51; JÄNTERA-JAREBORG, 2003, p. 207; BONOMI, 2001, p. 310).

45 Sobre esta cuestión particular, véase Álvarez Torné (2013) pp. 35-47.

46 TMC Asser Institute/Département de droit international UCL, Etude sur les régimes matrimoniaux des couples mariés et sur le patrimoine des couples non mariés dans le droit international privé et le droit interne des états membres de l'Union Européen effectuée à la demande de la Comission Européen Direction générale Justice et Affaires intérieues Unité A3 Coopération judiciare en matière civile, JAI/A3/2002/03, pp. 72-105 y pp. 106-143.
} 
A efectos prácticos, ello implicaría que aquellos cónyuges que tienen su residencia habitual en un Estado miembro donde resulta posible el ejercicio de la autonomía de la voluntad conflictual se encuentran claramente favorecidos en comparación con aquellos matrimonios internacionales que residen en un Estado miembro donde no resulta posible la elección del ordenamiento regulador del régimen económico matrimonial.

Dicha circunstancia, en combinación con la autonomía de la voluntad material, implicaría que la residencia en un determinado Estado miembro u otro no resulta cuestión baladí a efectos de determinar las posibilidades de elección de la ley aplicable al régimen económico matrimonial y dicha diferenciación solo podría solventarse, si cabe, "obligando" a los cónyuges que residen en un Estado miembro con legislación "menos" favorecedora de la autonomía de la voluntad a desplazarse a otros Estados miembro donde puedan "comprar" el régimen económico matrimonial que más se adecue a sus intereses.

El law shopping supone, en definitiva que los matrimonios con elemento de extranjería no gozan de los mismos beneficios en todos los Estados Miembros, de nuevo, por la diferenciación normativa material y conflictual que impide que los ciudadanos de la Unión Europea ejerzan sus derechos de modo continuo y heterogéneo en todo su territorio.

\subsection{LA INCERTIDUMBRE E INSEGURIDAD JURÍDICA EN CUANTO AL RÉGIMEN ECONÓMICO MATRIMONIAL}

Junto con los dos problemas descritos anteriormente, y que tienen en común el hecho de ser originados por una posición activa de, al menos, uno de los cónyuges, no cabe duda que el elemento de extranjería en la relación matrimonial -por ejemplo, por poseer ambos cónyuges distintas nacionalidades, diferentes residencias habituales o bienes localizados en distintos Estados- viene a generar una importante incertidumbre e inseguridad jurídica para los propios cónyuges, al desplegarse el interrogante de cuál de todos los ordenamientos jurídico conectados con el supuesto de hecho es el que finalmente regula el fenómeno del régimen económico matrimonial.

Consecuencia de lo anterior es la existencia en distintos momentos de la relación matrimonial ${ }^{47}$ de un panorama normativo rodeado de enormes especialidades y peculiaridades, atendiendo al propio diseño de las normas de conflicto en los distintos Estados miembro de la Unión Europea. Cónyuges que, inconscientemente se enfrentarán a situaciones relacionadas con el diferente resultado alcanzado por contener algunas normas de conflicto como primer punto de conexión la nacionalidad y otras la residencia habitual, o al cambio automático de ley aplicable al modificarse sus circunstancias personales.

En conclusión, la situación existente en el seno de la Unión Europea, carente de una normativa armonizada y transparente, se encuentra lejos de facilitar los interrogantes relativos a los derechos de propiedad de las parejas internacionales. Los problemas surgidos se referirán tanto a la averiguación de los tribunales competentes para resolver los posibles

47 Véase Impact Assessment study on community instruments concerning matrimonial property regimes and property of unmarried couples with transnational elements, elaborado por la EPEC (European evaluation consortium), 2010, pp. 7-10, que indica que los problemas referentes al régimen económico matrimonial se presentan en tres momentos del tiempo: antes o durante la relación matrimonial y, muy especialmente, cuando se atisba su disolución. 
conflictos en relación con la propiedad de los bienes, como a la determinación de la ley que la autoridad aplicará para resolver el asunto, si bien los cónyuges estarán especialmente interesados en el concreto régimen económico matrimonial que se aplica a su situación, para así saber qué bienes son de su propiedad.

\section{SOLUCIONES EXISTENTES EN LA ACTUALIDAD}

El análisis efectuado hasta el momento evidencia que la disparidad normativa material (2) y conflictual (3) genera una serie de problemas de enorme relevancia (4), sobre los que urge encontrar una solución. En este sentido, dicha situación se podría superar, bien en el plano material, bien en el plano conflictual. En el primero de ellos se podría aspirar a que las distintas legislaciones nacionales de los Estados miembros fueran convergiendo -armonización de los regímenes económico matrimoniales- o a que los Estados miembro ofrecieran idénticos regímenes económico matrimoniales -unificación de los regímenes económico matrimoniales- (5.1). Por su parte, en el plano conflictual (5.2), una unificación de las normas de conflicto de los regímenes económico matrimoniales también podría, en principio, resolver los problemas tanto de forum shopping y law shopping, como de incertidumbre e inseguridad jurídica a la que se enfrentan los matrimonios internacionales.

Los instrumentos unificadores o armonizadores de los regimen económicos matrimoniales que pretenden poner fin a los problemas descritos provienen, por el momento, de instituciones u organismos distintos a la Unión Europea, lo que se explica por dos razones. En primer lugar no existe en la actualidad ningún Reglamento de Derecho internacional privado de la Unión Europea que incluya en su ámbito de aplicación el régimen económico matrimonial ${ }^{48}$. Por otro lado, conviene recordar que la Unión Europea carece de competencia para la armonización y unificación del derecho sustantivo de familia, siendo esta materia, según la doctrina mayoritaria ${ }^{49}$, competencia legislativa exclusiva de cada Estado miembro.

\subsection{La ARMONIZACIÓN O UNIFICACIÓN SUSTANTIVA DEL RÉGIMEN ECONÓMICO MATRIMONIAL \\ Desde el plano material, y a la vista de la, aparentemente, inviable armonización o} unificación sustantiva de los regímenes económico matrimoniales acometida por la Unión Europea, dos son los instrumentos jurídicos que merecen ser tomados en consideración como potenciales soluciones frente a los problemas descritos: El Acuerdo franco-alemán instituyendo un régimen económico matrimonial de participación de las adquisiciones (5.1.1) y Los principios de derecho europeo de familia relativos a las relaciones patrimoniales de los cónyuges (5.1.2).

\footnotetext{
48 Sobre las futuras acciones legislativas de la Unión Europea en esta materia, véase el epígrafe 6.

49 Martiny (2011) p. 436. Además, véanse VV.AA. (JÄntera-jareborg, 2003, p. 195; Pintens, 2003, p. 22; Tenreiro y Ekström, 2003, p. 186, Tomasi et al., 2007, p. 341; Boele-Woelki, 2010, p. 51).
} 


\subsubsection{El Acuerdo franco-alemán instituyendo un régimen económico matrimonial de participación de las adquisiciones}

Este Acuerdo, concluido el 4 de febrero de 2010, consiste en un Convenio bilateral de derecho uniforme que recoge un régimen económico matrimonial secundario de carácter opcional ${ }^{50}$ para Alemania ${ }^{51}$ y Francia $^{52}$. Aunque la justificación de su aparición poco tiene de novedoso a la vista de los problemas descritos, lo cierto es que la manera en que pretende conseguirlo sí resulta pionera: se trata del primer ejemplo de unificación del derecho material de los regímenes económico matrimoniales a nivel intergubernamental ${ }^{53}$.

De acuerdo con lo dispuesto en el propio Convenio, el régimen económico matrimonial de participación de las adquisiciones podrá ser elegido por los cónyuges siempre que el derecho designado por la norma de conflicto, bien objetivamente, bien mediante la autonomía de la voluntad, sea el de un Estado contratante $e^{54}$, lo cual significa, en la actualidad, que siempre que el Derecho internacional privado de un determinado Estado designe el derecho alemán o francés, podrán acogerse los cónyuges a la elección de este régimen ${ }^{55}$. Una posibilidad que, en cualquier caso, podría ampliarse si en los próximos años algún Estado de la Unión Europea decide adherirse al Convenio, a la vista de su carácter abierto y de la invitación que las autoridades francesas y alemanas remitieron para promocionar el acuerdo $^{56}$.

Lejos de acometer en el presente trabajo un estudio pormenorizado del contenido concreto del régimen económico matrimonial ofrecido en el Convenio interesa, sin embargo, preguntarse si se trata de la solución global y definitiva en el proceso de unificación de los regímenes matrimoniales. Una cuestión que necesariamente ha de responderse negativamente, al menos, por dos razones.

En primer lugar, el hecho de que únicamente Alemania y Francia hayan participado en su elaboración y hayan basado el contenido concreto del régimen económico matrimonial ofrecido en el Convenio en lo dispuesto en sus legislaciones nacionales, puede haber desincentivado al resto de Estados miembro, "obligados" a adherirse a un Convenio que en nada a tomado en consideración lo dispuesto en su derecho interno sobre régimen econó-

50 El texto del Convenio puede encontrarse en el siguiente enlace: http://consulathonoraireallemagnerennes. fr/SitewebConsulatFichiersliens/Site\%20web\%20Consulat\%20Fichiers\%20liens/Dossier\%20presse\%20regime\%20matrimonial\%20commun.pdf (último acceso 10 de julio de 2015).

51 En Alemania, la ley de 15 de marzo de 2012, publicada en el Bundesgesetzblatt Jahrgang el 22 de marzo de 2012, introdujo el art. 1519 en el Código civil alemán, referente a la posibilidad de que los esposos convengan por capitulaciones matrimoniales el régimen opcional de participación en las ganancias.

52 El régimen económico matrimonial opcional se incorporó al derecho francés mediante la Ley no $213-98$ de 29 de enero de 2013 y entró en vigor el 1 de mayo de 2013. Dicha ley autorizó la ratificación del Acuerdo entre ambos países y el contenido del Acuerdo se publicó en el Journal Officiel de 12 de junio 2013, como anexo al Decreto no 2013-488 de 10 de junio de 2013.

53 Dethloff (2012) p. 538.

54 Art. 1 Acuerdo franco-alemán instituyendo un régimen económico matrimonial de participación de las adquisiciones.

55 También cabría la posibilidad de realizar una incorporación por referencia al Acuerdo a través del juego de la autonomía de la voluntad material según LAGARDE (2013) pp. 292-293.

56 Los Estados miembro que mayor interés mostraron para adherirse al acuerdo fueron Luxemburgo, Bulgaria y Hungría, con escasa influencia en la gran mayoría de Estados miembro (Fugardo Estivll (2013) p. 27). 
mico matrimonial. La muestra más clara de ello es que el régimen ofrecido en el Acuerdo es de tipo participación, de escasa tradición en los distintos Estados miembros como régimen legal ${ }^{57}$. Dicho factor, junto la circunstancia de que hoy en día son pocos los cónyuges que realizan pactos o capitulaciones matrimoniales para elegir un régimen económico matrimonial -recuérdese que la aplicación de este régimen económico matrimonial requiere de una designación expresa-, pone en entredicho la relevancia del Convenio ${ }^{58}$.

Por otro lado, debe indicarse que este Convenio podría, no solo no reducir la enorme heterogeneidad existente en derecho sustantivo, sino incluso incrementarla, al incentivar una "race of unification models", en la que algunos Estados miembros podrían ofrecer distintos regímenes económico matrimoniales mediante la previa conclusión de Tratados bilaterales $^{59}$, y ello con el problema añadido de que cada uno de dichos regímenes sería un "nuevo" derecho extranjero a aplicar por los operadores judiciales y extrajudiciales de cada ordenamiento jurídico.

\subsubsection{Los principios de derecho europeo de familia relativos a las relaciones} patrimoniales de los cónyuges elaborados por la Comisión de Derecho de familia europeo (CEFL).

Junto al ofrecimiento de regímenes económico matrimoniales comunes entre diversos Estados miembros que pretende conseguir el Acuerdo franco-alemán instituyendo un régimen económico matrimonial, los problemas descritos también podrían resolverse, al menos teóricamente, mediante una armonización de la materia, en la que los regímenes económico matrimoniales ofrecidos por cada Estado, bien legales bien opcionales, fueran convergiendo y asemejándose cada día más, todo lo cual implica referirse a la Comisión de Derecho de familia Europeo $(\mathrm{CEFL})^{60}$.

La CEFL nace en el año 2001, como una iniciativa puramente académica, independiente de cualquier organismo o institución, acogiendo a expertos de 26 jurisdicciones europeas, con el fin último de promover la armonización del derecho de familia en Europa. Su modus operandi consiste en la elaboración de una serie de principios surgidos de las características comunes ${ }^{61}$, o mejores opciones ${ }^{62}$, de los distintos ordenamientos jurídicos en liza, mediante la previa contestación de cuestiones comunes sobre determinadas áreas del derecho de familia por parte de expertos de cada Estado europeo ${ }^{63}$. No obstante, su

\footnotetext{
57 Sobre los regímenes legales en los Estados miembro de la Unión Europea, véase el epígrafe 2 del presente trabajo.

58 Su éxito, por tanto, dependerá, entre otros motivos, de la posible promoción que los operadores extrajudiciales del derecho realicen sobre el mismo (GonZález BeILfuss (2010) p. 416).

59 FöTsChl (2009) p. 403.

60 http://ceflonline.net/ (último acceso 29.06.2015).

61 Antokolskaia (2003) p. 160: "The common core method seems easiest to use because it makes justifying the choice of a particular rule very simple: the rule has been chosen merely because it represents a majority of jurisdictions".

62 Antokolskaia (2003) p. 162: ... select the better rule among the diverging rules existing in the national jurisdictions, or to engineer a better rule if no existing solution seems satisfactory".

63 Boele-WOelKi (2005) pp. 14-38.
} 
utilidad trasciende de los fines puramente armonizadores, erigiéndose como una base cualitativa que la Unión Europea podría considerar en un futuro proceso de integración jurídica sustantiva ${ }^{64}$.

El primer bloque de principios elaborado por la CEFL fue el referente al divorcio y a los alimentos entre esposos divorciados en el año 2004. Posteriormente vendrían los principios sobre responsabilidad parental en 2007 y, apenas hace dos años, los relativos a las relaciones patrimoniales entre cónyuges, que son los que particularmente interesan en este punto $^{65}$.

De la lectura de los principios, que además se ve acompañada de un estudio de derecho comparado que vendría a justificar la opción escogida para cada uno de ellos, puede concluirse que su calidad técnica está fuera de toda duda. Principios elaborados gracias al trabajo de los académicos u operadores prácticos del derecho de cada una de las jurisdicciones europeas, sin la "presión" añadida de estar representando a sus Estados ${ }^{66}$, que por su carácter completo y global, podrían regular un litigio internacional. Una posibilidad que, sin embargo, es actualmente una utopía, pues al menos en derecho de familia, las normas de conflicto -estatales, convencionales o elaboradas por el legislador de la Unión Europea-, solo permiten la elección de derecho elaborado por las autoridades legislativas competentes, en otras palabras, de disposiciones jurídicas de fuente estatal ${ }^{67}$.

Teniendo esto presente y que, por tanto, la elección de los principios como derecho aplicable a un litigio solo podría realizarse en la actualidad, mediante una incorporación por referencia a favor de los mismos siempre que lo permita el derecho designado por las normas de conflicto ${ }^{68}$, puede concluirse que, desde un punto de vista cortoplacista, no se prevé una reducción de los abusos de forum shopping o de las incómodas situaciones generadas por el law shopping. Los mayores beneficios de contar una codificación privada de tal calidad se esperan, por tanto, en aquellas situaciones en las que un legislador estatal opte por reformar las disposiciones referentes al régimen económico matrimonial de su derecho nacional, inspirándose en los principios elaborados por la $\mathrm{CEFL}^{69} \mathrm{y}$, por qué no, si finalmente el legislador de la Unión Europea se decide por ofrecer un régimen económico matrimonial europeo de carácter opcional ${ }^{70}$.

\footnotetext{
64 Campuzano díaz (2008) p. 108.

65 Todos los principios se encuentra publicados en varios idiomas en la página web de la CEFL, anteriormente referenciada.

66 Callies (2007) p. 475.

67 Se considera que aquellos cuerpos normativos no elaborados por el legislador estatal carecen de la estructura, sistematización y transparencia necesarias como para poder ser derecho perfectamente válido para resolver un litigio según VV.AA. (Fountoulakis, 2006, p. 303-329; Boele-Woelki, 2010, p. 163).

68 Boele-WOelKi et al. (2013) p. 38.

69 Recientemente, los principios de la CEFL inspiraron los legisladores portugueses (Lei do divorcio 2008), noruegos (Children Act 2010) y croatas (Bill 2013), en las reformas referentes al divorcio y responsabilidad parental, respectivamente.

70 Dicha alternativa puede resultar una utopía en el momento presente, pero ya ha sido considerada por la más relevante doctrina de Derecho internacional privado de familia (AgELL, 1998, p. 20; FöTSCHL, 2009, 403; Boele-Woelki y Jänterä Jareborg, 2011, p. 56; Verbeke, 2011, pp. 198-200; Martiny, 2011, p. 444; BoeleWOELKI, 2014, p. 28).
} 
5.2. La unificaCión CONFLICTUAL del RÉGIMEN ECONÓMICO MATRIMONIAL: EL Convenio de La Haya sobre la ley aplicable a los Regímenes matrimoniales

Tras considerar los instrumentos existentes en términos sustantivos, es turno de analizar si existen mecanismos efectivos desde el punto de vista de la unificación de las normas de conflicto de los Estados miembro. En otras palabras, interesa averiguar si la problemática de los regímenes matrimoniales ha estado también presente en la agenda de organizaciones y grupos con el fin último de ofrecer soluciones focalizadas en el plano conflictual a nivel internacional. Entre ellos destaca la labor de la Conferencia de La Haya de Derecho internacional, que en 1978 elaboró el Convenio de La Haya sobre la ley aplicable a los regímenes matrimoniales ${ }^{71}$. Un Convenio ratificado actualmente solo por tres Estados miembro: Francia, Holanda y Luxemburgo ${ }^{72}$.

La finalidad perseguida con la elaboración de esta norma multilateral es el ofrecimiento de normas de conflicto comunes en materia de régimen económico matrimonial lo que implica, al menos para los Estados miembro que lo han ratificado, que con independencia del tribunal que conozca del asunto, las normas de conflicto que resultarán de aplicación serán las mismas. Una medida que, sin duda alguna, mitigaría gran parte de los problemas descritos pero que, sin embargo, al no contar con un alto grado de aceptación entre los Estados miembros, no puede conseguir, globalmente, dicho fin. ¿Cuáles han sido las circunstancias que explican que esta herramienta cuente con escaso poder resolutivo? Sin perjuicio de otras razones de política legislativa, el contenido del Convenio resulta controvertido desde, al menos, dos puntos de vista.

Primeramente, la opción por la mutabilidad automática ${ }^{73}$, en virtud de la cual teniendo lugar determinados cambios en las circunstancias fácticas o personales de los cónyuges se producía una modificación del derecho aplicable, no tuvo una buena acogida en términos generales. Pese a contar con la enorme ventaja de remediar la excesiva rigidez de los factores de conexión y la aplicación de una ley con la que los cónyuges no se encontraran vinculados, no fueron pocos los autores que destacaron los problemas de incertidumbre e inseguridad jurídica, no solo para los cónyuges sino también para los terceros que contratan con ellos, pues lo cierto es que detrás de cada cambio de ley aplicable se esconde, en algunos casos, un cambio de régimen económico matrimonial ${ }^{74}$.

Otra de las aristas del Convenio fue la posibilidad de elección de la lex rei sitae, lo cual no conduce sino a la posibilidad, en algunos supuestos, de elegir múltiples leyes para regular el régimen económico matrimonial ${ }^{75}$. Una opción que pretendía buscar un acerca-

\footnotetext{
${ }^{71}$ La versión española del Convenio se encuentra disponible en Borras Rodríguez y GonzÁlez Campos (2008) pp. 201-207 y también en http://www.hcch.net/upload/conventions/txt25es.pdf (último acceso 29.06.2015). Para un análisis de las opciones escogidas en cada una de las partes del Convenio y el proceso de negociación del mismo, véase VON OvERBECK (1978).

72 Este Convenio se encuentra igualmente firmado por Austria y Portugal, aunque no han procedido a su posterior ratificación (REVILLARD (2008) p. 34).

73 Art. $7.2^{\circ}$ párr. CHLARM.

74 Cfr. VV.AA (Lequette, 1994, pp. 167-170, Courbe, 2007, p. 182; Mayer y Heuzé, 2010, p. 557, Clavel, 2012, pp. 429-430).

75 Art. 3.3 CHLARM.
} 
miento con los países anglosajones, en los que dicha posibilidad se encuentra perfectamente prevista, pero que resulta minoritaria en los Estados miembro de tradición civilista, que optan por la regulación unitaria del régimen económico matrimonial y que vendría a explicar parte del porqué de la falta de éxito del Convenio ${ }^{76}$.

Se tratan pues, ambas, de soluciones que se adoptaron desde un consenso que, en cierta medida, pudo no resultar pacífico en todo momento y que, a la postre, se tradujo en un escaso número de ratificaciones y, por tanto, limitada eficacia para mitigar las dificultades analizadas.

\section{EL FUTURO ESCENARIO DEL RÉGIMEN ECONOMICO MATRIMONIAL: ACCIONES LEGISLATIVAS DE LA UNIÓN EUROPEA}

Consciente de que los problemas descritos pueden atentar contra la libre circulación de personas en la Unión Europea ${ }^{77}$ (art. 21 del Tratado de Funcionamiento de la Unión Europea $^{78}$ ) y poner en entredicho el funcionamiento del mercado interior ${ }^{79}$, la Comisión Europea presentó una Propuesta de Reglamento del Consejo relativo a la competencia, la ley aplicable el reconocimiento y la ejecución de resoluciones en materia de regímenes económico matrimoniales ${ }^{80}$. Un texto unificado de régimen económico matrimonial, con normas referentes a los tres sectores del Derecho internacional privado, y cuyas líneas maestras se trazarán a continuación.

En el sector de la competencia judicial internacional, la Propuesta de Reglamento diferencia con claridad los supuestos de régimen económico matrimonial conectados con el divorcio y aquellos relacionados con el fenómeno sucesorio. En ambos casos el objetivo del legislador de la Unión Europea es la concentración de asuntos bajo un mismo tribunal estatal $^{81}$, lo cual queda justificado por la evidente conexión temática de dichos litigios. Para

\footnotetext{
76 Sobre esta cuestión, véase VV.AA. (LousSOUARn, 1979, pp. 9-10; LienArd-Ligny, 1981, pp. 319-320; REVILLARD, 2008, p. 23)

77 Comunicación de la Comisión al Parlamento Europeo, al Consejo, al Comité Económico y Social Europeo y al Comité de las Regiones: Disipación de las incertidumbres en torno a los derechos patrimoniales de las parejas internacionales (COM (2011) 125 final) p. 5.

78 DO C 326/49, de 26 de octubre de 2012.

79 Véase el documento de trabajo de la Comisión Resumen de la evaluación del impacto del impacto (SEC (2011) 328 final) que acompaña a la Comunicación de la Comisión al Parlamento Europeo, al Consejo, al Comité Económico y Social Europeo y al Comité de las Regiones: Disipación de las incertidumbres en torno a los derecho patrimoniales de las parejas internacionales (COM (2011) 125 final) y a la Propuesta de Reglamento del Consejo relativo a la competencia, la ley aplicable, el reconocimiento y la ejecución de resoluciones en materia de regímenes económico matrimoniales (COM (2011) 126 final) p. 8.

80 Propuesta de Reglamento del Consejo relativo a la competencia, la ley aplicable, el reconocimiento y la ejecución de resoluciones en materia de regímenes económico matrimoniales (COM (2011) 126 final). Ese mismo día también fue presentada la Propuesta de Reglamento relativa a la competencia, la ley aplicable, el reconocimiento y la ejecución de resoluciones en materia de efectos patrimoniales de las uniones registradas (COM (2011) 127 final).

81 Exposición de motivos de la Propuesta de Reglamento, apartado 5.2. Véase también VV.AA. (VIARENGO, 2011, p. 201; Campuzano Díaz, 2011, p. 237; Bonomi, 2011, p. 218).
} 
ello, la Propuesta de Reglamento emplea diferentes fórmulas ${ }^{82}$ : la extensión automática de competencia de los tribunales competentes en las sucesiones (art. 4 de la Propuesta de Reglamento) y la necesaria autonomía de la voluntad de los cónyuges para que sobre el régimen económico matrimonial decida el tribunal designado en virtud del Reglamento Bruselas II $b^{8} s^{83}$ (art. 3 de la Propuesta de Reglamento) ${ }^{84}$. El resto de supuestos tienen cabida en el art. 5 de la Propuesta de Reglamento, que designa unos tribunales competentes ordenados jerárquicamente.

Por lo que respecta a la ley aplicable, y denotando una clara influencia del contenido del Convenio de La Haya de 1978 excepto por las cuestiones "polémicas" anteriormente descritas, la Propuesta de Reglamento ofrece una autonomía de la voluntad conflictual limitada, consistente en la posibilidad de elegir una única ley de entre la nacionalidad o la residencia habitual de cualquiera de los cónyuges (art, 16 Propuesta de Reglamento) ${ }^{85}$. La designatio iuris, en cualquier caso, no se encuentra limitada a un único momento del tiempo, pudiendo los cónyuges cambiar el derecho aplicable en cualquier momento de la relación matrimonial (art. 18 Propuesta de Reglamento). No habiéndose hecho uso de tal facultad, se producirá la entrada en escena de las conexiones objetivas (art. 17 Propuesta de Reglamento), cuyo primer criterio es la primera residencia habitual común de los cónyuges después de la celebración del matrimonio, seguido por la nacionalidad común y, como conexión de cierre, la ley de los vínculos más estrechos.

El reconocimiento y ejecución de resoluciones judiciales y documentos públicos y transacciones judiciales es el tercer sector del Derecho internacional privado regulado en la Propuesta de Reglamento. Se ha optado aquí por una postura más bien "conservadora” en virtud de la cual pese a que el reconocimiento resulta automático entre los distintos Estados miembros, todavía se sigue exigiendo la declaración de ejecutividad para conseguir la ejecución material de una resolución ${ }^{86}$. En este sentido, el régimen ofrecido es idéntico al del Reglamento 44/20001, mas no al del reciente Reglamento Bruselas I bis ${ }^{87}$, en el que, al

82 Fontanellas Morell (2012) p. 266.

83 Reglamento no 2201/2003 del Consejo, de 27-11-2003, relativo a la competencia, el reconocimiento y la ejecución de resoluciones judiciales en materia matrimonial y responsabilidad parental (DO L 338 de 23 de diciembre de 2003).

84 La coordinación entre todos los instrumentos de Derecho internacional privado de familia y sucesiones no resulta pacífica. Sobre esta cuestión véase, QuinZÁ REDOndo Y Gray (2013) pp. 513-540.

85 En los instrumentos de Derecho internacional privado de familia y sucesiones de la Unión Europea, la autonomía de la voluntad se ha consagrado como primera conexión, ya no solo del régimen económico matrimonial, sino también del resto de materias conexas. Cfr. VV.AA (JaYMe, 2009, pp. 1-10; Carruthers, 2012, pp. 881-913; Nagy, 2012, 576-586; RevilLard, 2013, pp. 487-502).

86 Carrillo Pozo (2012) pp. 120-121. De hecho, recientemente, el Parlamento Europeo, en un estudio sobre el funcionamiento del Reglamento Bruselas II bis (Informe de la Comisión al Parlamento Europeo, al Consejo y al Comité económico y social europeo sobre la aplicación del Reglamento 2201/2003, COM (2014) 225 final, p. 10), ha destacado la posibilidad de extender la abolición del exequatur a otras categorías en línea con los últimos instrumentos de Derecho internacional privado de la Unión Europea.

87 Reglamento (UE) no 1215/2012 del Parlamento europeo y del Consejo de 12 de diciembre de 2012 relativo a la competencia judicial, el reconocimiento y la ejecución de resoluciones judiciales en materia civil y mercantil (DO L 351/1 de 20 de diciembre de 2012). 
menos teóricamente, queda abolido el exequatur y por ello, en cierto modo, se puede considerar desfasado ${ }^{88}$.

Dejando de lado los aspectos puramente técnicos del texto legal, la pregunta central sería, ¿constituye la unificación de las normas de Derecho internacional privado acometida por el legislador de la Unión Europea una solución satisfactoria a los problemas descritos? Por lo que respecta al forum shopping no cabe duda de que mediante el ofrecimiento de normas de conflicto idénticas, unida a la de los criterios de competencia judicial internacional, se consigue evitar las ventajas del cónyuge más informado, pues conozca el tribunal que conozca, el derecho aplicado será siempre el mismo. Paralelamente, el ofrecimiento de homogéneos niveles de autonomía de la voluntad conflictual elimina las desventajas del law shopping, pues los ciudadanos de la Unión Europea podrán "comprar" el mismo derecho en cualquier Estado miembro. Finalmente, no cabe duda que la incertidumbre e inseguridad jurídica también se verán reducidas, al quedar abocados los ciudadanos a la aplicación de las mismas normas en todos los Estados miembro.

Podría concluirse, en definitiva, que la acción del legislador de la Unión Europea mediante la introducción de un Reglamento de Derecho internacional privado, cuando este sea de aplicación ${ }^{89}$, resulta necesaria y ciertamente mejora a todos los niveles la situación existente en la actualidad.

\section{CONCLUSIONES}

La investigación realizada parte de un dato sociológico característico de nuestros días: la creciente internacionalización de las relaciones humanas, también jurídicas. A ello han contribuido, desde un punto de vista geográfico y político, la libre circulación de los ciudadanos de la Unión Europea, así como la entrada creciente de nacionales de terceros Estados, que ha repercutido directamente en el aumento de matrimonios internacionales. Sin embargo, este fenómeno social, al menos hasta el momento presente, no se ha visto adecuadamente acogido en las normas reguladoras de tales situaciones jurídicas en el seno de la Unión Europea.

La dispersión y divergencia normativa material y conflictual en materia de régimen económico matrimonial es potencialmente generadora de un conjunto de problemas, como son el forum shopping, el law shopping y la enorme incertidumbre e inseguridad jurídica a la que se enfrentan los matrimonios internacionales, que no han recibido una solución global y definitiva en la actualidad, ni desde un punto de vista material -Acuerdo franco-alemán instituyendo un régimen económico matrimonial y/o principios de derecho europeo de

\footnotetext{
88 Situación idéntica al Reglamento sobre sucesiones, tal y como apunta Rodríguez Mateos (2014) pp. 44-45.

89 Consejo de la Unión Europea. Estado de los trabajos de la Propuesta de Reglamento del Consejo relativo a la competencia, la ley aplicable y el reconocimiento y la ejecución de resoluciones en materia de regímenes económico matrimoniales y de la Propuesta del Consejo relativo a la competencia, la ley aplicable y el reconocimiento y la ejecución de resoluciones en materia de efectos patrimoniales de las uniones registradas, de 24 de noviembre de 2014, 15888/1/14 JUSTCIV 304, donde parece sugerirse que el "retraso" en la presentación del Reglamento de régimen económico matrimonial proviene de su tramitación paralela con el Reglamento en materia de efectos patrimoniales de las uniones registradas.
} 
familia relativos a las relaciones patrimoniales de los cónyuges- ni desde un punto de vista conflictual -Convenio de La Haya de 1978 sobre la ley aplicable a los regímenes matrimoniales-.

La Propuesta de texto unificado sobre régimen económico matrimonial está llamado a ser a corto plazo el último instrumento del proceso de europeización del Derecho internacional privado de familia y sucesiones y mitiga en buena medida los problemas descritos a través de la unificación de las normas de conflicto.

\section{BIBLIOGRAFÍA CITADA}

Agell, Anders (1998): "The division of property upon divorce from a European perspective", VV.AA., Liber amicorum Marie-Thérèse Meulders-Klein: droit comparé des personnes et de la famille (Bruselas, Bruylant) pp. 1-20.

Álvarez Torné, María (2013): La autoridad competente en materia de sucesiones internacionales: el nuevo Reglamento de la UE (Madrid, Marcial Pons).

Antokolskaia, Masha (2003): "The "better law" approach and the harmonisation of family law”, Boele-Woelki, Katharina (ed.): Perspectives for the unification and harmonisation of family law in Europe, (Antwerpen, Intersentia) pp. 194-216.

AÑoveros Terradas, Beatriz (2010): "Los pactos prematrimoniales en previsión de ruptura en el derecho internacional privado", Anuario español de derecho internacional privado, núm. 10: pp. 441-469.

Ballarino, Tito. (2011): Diritto internazionale privato italiano (Padova, Cedam, $7^{\circ} \mathrm{ed}$.).

Batiffol, Henri (1974): "Le pluralisme des méthodes en droit international privé", en VV.AA., Recueil des courses, número 139 (La Haya, Nijhoff).

Boele-WOelKi, Katharina (2014): "Why and how to accommodate an Optional European Family Law”, VV.AA., Festschrift für Dieter Martiny zum 70. Geburtstag, (Mohr Siebeck, Tübingen) pp. 27-40.

Boele-WOelKI, Katharina et al. (2013): Principles of European family law regarding property relations between spouses (Cambridge-Antwerp-Portland, Intersentia).

Boele-Woelki, Katharina y Jänterä JAREBOrG, Maarit (2011): "Initial results of the CEFL in the field of property relationships between spouses", Boele-Woelki, Katharina et al. (eds.), The future of family property in Europe (Cambridge, Intersentia) pp. 47-64.

BOELE-WOELKI, Katharina (2010): Unifying and harmonizing substantive law and the role of conflict of laws (Leiden, Nijhoff).

Boele-Woelki, Katharina (2005): "The working method of the Commission on European family law",Boele-Woelki, Katharina (ed.), Common core and better law in European family law (Antwerp, Intersentia) pp. 14-38.

Bonomi, Andrea (2011): "The Interaction among the Future EU Instruments on Matrimonial Property, Registered Partnerships and Successions", Yearbook of private international law, vol. 13: pp. 217-231.

Bonomi, Andrea (2006): "Les régimes matrimoniaux en droit international privé comparé", en VV.AA., Les régimes matrimoniaux en droit comparé et en droit international privé (Gèneve, Droz) pp. 59.75. 
Bonomi, Andrea (2001): "Il regolamento comunitario sulla competenza e sul riconoscimiento in materia matrimoniale e di potestà dei genitori", Rivisita di diritto internazionale, vol. 84, núm. 2: pp. 298-346.

Borras Rodríguez, Alegría y González Campos, Julio (2008): Recopilación de los Convenios de La Haya de Derecho internacional privado (1951-2007) (Madrid, Marcial Pons).

Borrás, Alegría (2003): "Competencia judicial, reconocimiento y ejecución de decisiones en materia matrimonial: el Reglamento 1347/2000 (Bruselas II)”, Revista jurídica de Catalunya, vol. 102, núm. 2: pp. 361-386.

Calvo Caravaca, Alfonso Luis y Carrascosa González, Javier (2014): Derecho internacional privado vol. II (Granada, Comares, $15^{\circ}$ ed.).

Callies, Graf-Peter (2007): “The making of transnational contract law", Indiana journal of global legal studies, vol. 14, núm. 2: pp. 469-483.

Campuzano Díaz, Beatriz (2011): "The Coordination of the EU Regulations on Divorce and Legal Separation with the Proposal on Matrimonial Property Regimes", Yearbook of private international law, vol. 13: pp. 233-254.

Campuzano Díaz, Beatriz (2008): "La propuesta de reforma del Reglamento 2201/2003 en materia matrimonial”, Di Filippo, Marcello et al. (coords.), Hacia un derecho conflictual europeo: realizaciones y perspectivas (Sevilla, Secretariado de publicaciones de la Universidad de Sevilla) pp. 93-119.

Carlier, Jean-Yves (2002): "Estatuto personal y multiculturalidad: el papel de la autonomía de la voluntad”, Calvo Caravaca, Alfonso Luis y Iriarte Ángel, José Luis (eds.), Estatuto personal y multiculturalidad (Madrid, Colex).

Carrillo Pozo, Luis F. (2012): "Eficacia en España de las resoluciones extranjeras en materia de efectos económicos del matrimonio", Cuadernos de derecho transnacional, vol. 4, núm. 1: pp. 86-121.

CARruthers, Janeen (2012): "Party autonomy in the legal regulation of adult relationships: place for party choice in private international law", International and comparative law quarterly, vol. 61, núm. 4: pp. 881-913.

Cervilla Garzón, María Dolores (2013): Los acuerdos prematrimoniales en previsión de ruptura. Un estudio de Derecho comparado (Valencia, Tirant lo Blanch).

Clarkson, Christopher y Hill, Jonathan (2006): The conflict of laws (Oxford, Oxford University press, $3^{\circ} \mathrm{ed}$.)

Clavel, Sandrine (2012): Droit international privé (Paris, Dalloz, $3^{\circ}$ ed.).

Collins, Lawrence (2012): Dicey, Morris \& Collins on the conflict of laws vol. II (Londres, Sweet \& Maxwell, $15^{\circ}$ ed.).

Courbe, Patrick (2007): Droit international privé (Paris, Hachette).

Dethloff, Nina (2012): “The Franco-German Optional Matrimonial Property Regime A Trailblazer for the Alignment of Family Law?", Rabels Zeitschrift fuer auslaendisches und internationales Privatrecht, vol. 76, Num. 3: pp. 509-539.

Dethloff, Nina (2003): "Arguments for the unification and harmonization of family in Europe", Boele-Woelki, Katharina (ed.), Perspectives for the unification and harmonisation of family law in Europe (Antwerpen, Intersentia) pp. 54-64. 
Di FILIPPO, Marcello (2005): "Concepciones nacionales en materia de familia y Derecho internacional privado comunitario: breves notas sobre el Reglamento N. 2001/2003 y el ordenamiento italiano", La libre circulación de resoluciones judiciales en la Unión Europea (Sevilla, Actas de Seminarios, Secretariado de Publicaciones de la Universidad de Sevilla) pp. 201-205.

Diago Diago, María Pilar (1999): Pactos o capitulaciones matrimoniales en derecho internacional privado (Zaragoza, Colección El Justicia de Aragón).

DutTA, Anatol (2010): "Cross-border enforcement of English ancillary relief orders- Fog in the cannel, Europe cut off?" Family law Journal, Abril 2010: pp. 385-390.

Fawcett, James y Carruthers, Janeen (2008): Cheshire, North \& Fawcett Private international law (Oxford, Oxford University press, $14^{\circ} \mathrm{ed}$.)

Fontanellas Morell, José María (2012): "Una primera lectura de las Propuestas de Reglamento comunitario en materia de regímenes económico matrimoniales y de efectos patrimoniales de las uniones registradas", Parra, Carmen (ed.), Nuevos Reglamentos comunitarios y su impacto en el derecho catalán (Barcelona, Bosch Editor) pp. 257-290.

FöTSCHL, Andreas (2009): "The common optional matrimonial property regime of Germany and France. Epoch-Making in the unification of law", Yearbook of private international law, vol. 11: pp. 395-404.

Fountoulakis, Christiana (2006): “The parties' choice of neutral law' in international sales contract”, European journal of law reform, vol. 7, núms. 3-4: pp. 303-329.

Fugardo Estivll, José María (2013): El nuevo régimen económico matrimonial de participación en las ganancias. Derecho matrimonial europeo (Barcelona, Bosch).

Garofalo, Luciano (1997): I rapporti patrimoniali tra coniugi nel diritto internazionale privato (Torino, Giappichelli editore, $2^{\circ} \mathrm{ed}$.).

Gaspar Lera, Silvia (2012): "Los acuerdos prematrimoniales en derecho inglés. Validez, eficacia y discrecionalidad judicial", Indret, núm.3: pp. 1-25.

Gómez CAMPelo, Esther (2008): Los regimenes matrimoniales en Europa y su armonización (Madrid, Reus).

GonzÁlez Beilfuss, Cristina (2010): "El acuerdo franco-alemán instituyendo un régimen económico matrimonial común”, Anuario español de derecho internacional privado, núm. 10: pp. 397-416.

GonzÁlez BeIlfuss, Cristina (2004): "Relaciones e interacciones entre derecho comunitario, derecho internacional privado y derecho de familia europeo en la construcción de un espacio judicial común", Anuario español de Derecho internacional privado, núm. 4: pp. 117-190.

Harris-SHort, Sonia y Miles, Joana (2011): Family Law. Text, Cases and materials (Oxford, Oxford University press, $2^{\circ} \mathrm{ed}$.).

JÄNTERÄ JAREBORG, Maarit (2003): "Unification of international family law in Europe - A critical perspective", Boele-Woelki, Katharina (ed.): Perspectives for the unification and harmonisation of family law in Europe (Antwerp, Intersentia) pp. 194-216.

JAYME, Erik (2009): "Party autonomy in international family and succession law: new tendencies", Yearbook of private international law, vol. 11: pp. 1-10. 
Kroll, Kathrin (2008): "Unifications of conflicts of law in Europe- Matrimonial property regimes-“, Boele Woelki, Katharina y Sverdrup, Tone (eds.), European challenges in contemporary family law (Antwerpen, Intersentia) pp. 379-393.

LaGARDE, Paul (2013): "Instrument optionnel international et droit international privé-subordination ou indépendance", VV.AA., A Commitment to private international law. Essays in honour of Hans Van Loon (Cambridge, Intersentia) pp. 487-502.

LEQUETTE, Yves: "Le droit international privé de la famille à l'épreuve des conventions internationale", VV.AA., Recueil des courses, número 246 (La Haya, Nijhoff).

LienARD-Ligny, Monique (1981): "Régime matrimonial en droit international privé et la Convention de La Haye du 14 mars 1978”, Annales de la Faculté de droit de Liège, vol. 26 : pp. 312-337.

Loussouarn, Yvon (1979): "La Convention de la Haye sur la loi applicable aux régimes matrimoniaux", Journal du droit international, vol. 106: pp. 5-20.

Lowe, Nigel y Douglas, Gillian (2007): Bromley's Family Law (Oxford, Oxford University Press, $10^{\circ}$ ed.).

Martiny, Dieter (2011): "Is Unification of Family Law Feasible or even Desirable?", VV.AA., Towards a European civil code (Alphen aan den Rijn, Wolters Kluwer) pp. 429458.

Mayer, Pierre y Heuzé, Vincent (2010): Droit international privé (Paris, Montchrestien, $10^{\circ}$ ed.)

Meeusen, Johan (2007): "System shopping in European private international law in family matters", en Meeusen, Johan, et al., International family law for the European Union (Antwerpen, Intersentia) pp. 260-278.

Miles, Joana (2012): "England and Wales", en Scherpe, Jens (ed.), Marital agreements and private autonomy in comparative perspective (Oxford, Hart) pp. 89-121.

NAGY, Csongor István (2012): "What functions may party autonomy have in international family and succession law"? A EU perspective", Nederlands International Privaatrecht, núm.4 : pp. 576-586

PInTENS, Walter (2003): "Europeanisation of family law”, Boele-Woelki, Katharina (ed.), Perspectives for the unification and harmonisation of family law in Europe (Antwerp, Intersentia) pp. 3-34.

Probert, Rebecca (2012): Cretney and Probert's family law (Londres, Sweet \& Maxwell, 8º ed.)

Queirolo, Ilaria y CARPAneto, Laura (2012).: "Considerazioni critiche sull'estensione dell'autonomia privata a separazione e divorzio nel regolamento "Roma III»", Rivista di Diritto Internationale Privato e Processuale, vol. 48, núm. 1: pp. 59-86.

Quinzá Redondo, Pablo y Gray, Jacqueline (2013): "La (des) coordinación entre la Propuesta de Reglamento de régimen económico matrimonial y los Reglamentos en materia de divorcio y sucesiones", Anuario español de Derecho internacional privado, vol. 13: pp. 513-540.

Revillard, Mariel (2013): "L'autonomie de la volonté dans les relations de famille internationales: regards sur les récents instruments internationaux", VV.AA., A Commitment 
to private international law. Essays in honour of Hans Van Loon (Cambridge, Intersentia) pp. 487-502

Revillard, Mariel (2008): Pratique de la convention de La Haye sur la loi applicable aux régimes matrimoniaux. Commentaire \& Formules (Paris, Defrénois $2^{\circ}$ ed.)

Rodríguez Mateos, Pilar (2014): "La sucesión por causa de muerte en el derecho de la Unión Europea”, Revista electrónica de estudios internacionales, núm. 27: pp. 1-59.

SÁNCHEZ JimÉnEZ, María Ángeles (2013): El divorcio internacional en la Unión Europea: jurisdicción y ley aplicable (Cizur Menor, Thomson Reuters Aranzadi).

Tenreiro, Mario y EKström, Monika (2003): "Unification of private international law in family matters within the European Union”, Boele-Woelki, Katharina (ed.), Perspectives for the unification and harmonisation of family law in Europe (Antwerp, Intersentia) pp. 185-193.

TOMASI, Laura et al. (2007): "Characterization in family matters for purposes of European private international law, Meeusen, Johan, et al., International family law for the European Union (Antwerpen, Intersentia) pp. 341-385.

VAquero López, Carmen (2006): "Los regímenes matrimoniales en un espacio de libertad, seguridad y justicia: apuntes sobre la codificación comunitaria de las normas sobre competencia judicial internacional, conflicto de leyes y reconocimiento y ejecución de decisiones judiciales", Anuario español de derecho internacional privado, núm. 6: pp. 195208.

VerbeKe, Alain (2001): "Perspectives for an international marital contract", Maastricht journal of European and comparative law, vol. 8, núm. 2: pp. 189-200.

Viarengo, Ilaria (2011): "The EU Proposal on Matrimonial Property Regimes -Some General Remarks", Yearbook of private international law, vol. 13: pp. 199-216.

VIARENGO, Ilaria (1996): Autonomia della volontà e rapporti patrimoniali tra coniuigi nel diritto internazionale privato (Padova, Cedam)

Von Overbeck, Alfred (1978): "Explanatory Report", Actes et documentes de la Treizième sesión. Tome II. Matrimonial property regimes (La Haya, Bureau Permanent de la Conférence) pp. 329-377.

\section{SENTENCIAS CITADAS}

Charman v Charman [2007] EWCA Civ. 503

Frankel's Estate v The Master 1950 (1) S.A. 220 (AD)

Miller v Miller; McFarlane v McFarlane [2006] UKHL 24

Radmacher v Granatino [2010] UKSC 42

Re De Nicols [1900] 2 Ch 410

Re Egerton's Will Trusts [1956] Ch. 593

Welch v Tennent [1891] A.C. 639

White v White [2000] 1 UKHL 54 


\section{NORMAS LEGALES CITADAS}

1. Legislación de la Unión Europea

Reglamento no 2201/2003 del Consejo, de 27-11-2003, relativo a la competencia, el reconocimiento y la ejecución de resoluciones judiciales en materia matrimonial y responsabilidad parental (DO L 338 de 23 de diciembre de 2003).

Propuesta de Reglamento del Consejo relativo a la competencia, la ley aplicable, el reconocimiento y la ejecución de resoluciones en materia de regímenes económico matrimoniales de 16 de marzo de 2011 (COM (2011) 126 final).

Propuesta de Reglamento del Consejo relativo a la competencia, la ley aplicable, el reconocimiento y la ejecución de resoluciones en materia de efectos patrimoniales de uniones registradas de 16 de marzo de 2011 (COM (2011) 127 final).

Reglamento (UE) no 1215/2012 del Parlamento europeo y del Consejo de 12 de diciembre de 2012 relativo a la competencia judicial, el reconocimiento y la ejecución de resoluciones judiciales en materia civil y mercantil (DO L 351/1 de 20 de diciembre de 2012).

2. Legislación de Inglaterra y Gales

Wills Act 1837 (1837 C.26 (Regnal. 7 Will 4 and 1 Vict)

Married Women's Property Act 1882 (1882 C.75 (Regnal. 45 and 46 Vict).

Administration Estates Act 1925 (1925 C.23 (Regnal 15 and 16 Geo 5).

Law Reform Married Women and Tortfeasors Act 1935 (1935 C.30 (Regnal. 25 and 26 Geo 5).

Married Women's Property Act 1964 (1964 C. 19).

Divorce Reform Act 1969 y la Matrimonial Proceedings and Property Act 1970 (1970 C. 45).

Matrimonial Causes Act 1973 (1973 C. 18).

Inheritance Act 1975 (1975 C. 63).

Domestic Proceedings and Magistrates'Court Act 1978 (1978 C. 22).

Family Law Act 1996 (1996 C. 27).

Equality Act 2010 (2010 C. 15).

Family Procedure Rules 2010 (2010 No. 2955 (L.17).

Inheritance and Trustee's Act 2014 (2014 C.16) 